\title{
Neurological Manifestations of West Nile Virus Infection
}

\author{
Jodie M. Burton, Ralph Z. Kern, William Halliday, David Mikulis, \\ James Brunton, Margaret Fearon, Caitlin Pepperell, Cheryl Jaigobin
}

\begin{abstract}
Background: Over the past four years, West Nile virus (WNV) has become a significant health issue in North America. In 2002, WNV infection made its first appearance in the human population in Canada. Methods: Patients who presented to the University Health Network and Mount Sinai Hospital in Toronto with neurological disease attributed to WNV infection were identified and followed by the neurology service. Clinical features and results of laboratory, electrodiagnostic, radiological and pathological studies are presented. Results: In August and September 2002, 26 patients were admitted with WNV infection; 14 presented with neurological illness. Encephalitis was the most common presentation (11 patients). Eleven patients developed neuromuscular disease; two at presentation and nine after encephalitis. While the majority had a motor process that localized to the anterior horn cell and/or motor neuron, two patients had evidence of a demyelinating neuropathy and one a sensorimotor axonal neuropathy. Less common manifestations included rhombencephalitis, ataxia, myelopathy and parkinsonism. Death occurred in four patients; two $>75$ years of age, and two who were immunocompromised. Conclusions: The most common neurological manifestation of WNV infection was encephalitis with subsequent neuromuscular involvement. The diversity of clinical and pathological findings, however, suggests widespread involvement of the central and peripheral nervous system. A poorer prognosis for neurological recovery and overall survival was seen in older and immunocompromised patients.
\end{abstract}

RÉSUMÉ: Manifestations neurologiques de l'infection par le virus du Nil occidental. Introduction: Depuis quatre ans, le virus du Nil occidental (VNO) est devenu une menace importante pour la santé en Amérique du nord. Au Canada, l'infection par le VNO a fait son apparition pour la première fois chez les humains en 2002. Méthodes: Les patients qui ont consulté au University Health Network et au Mount Sinai Hospital à Toronto pour une maladie neurologique attribuée à l'infection par le VNO ont été identifiés et suivis en neurologie. Nous présentons les données cliniques, les résultats biochimiques et les épreuves électrodiagnostiques, radiologiques et anatomopathologiques. Résultats: En août et en septembre 2002, 26 patients porteurs d'une infection par le VNO ont été hospitalisés, dont 14 avaient des manifestations neurologiques. Onze patients ont consulté pour une encéphalite. Onze patients ont présenté une maladie neuromusculaire, dont deux initialement et neuf à la suite d'une encéphalite. La majorité avaient une atteinte motrice localisée à la corne antérieure et/ou au neurone moteur, deux patients avaient une neuropathie démyélinisante et un avait une neuropathie axonale sensitivomotrice. La rhombencéphalite, l'ataxie, la myélopathie et le parkinsonisme étaient plus rares. Quatre patients sont morts, dont deux qui avaient plus de 75 ans et deux qui étaient immunocompromis. Conclusions: La manifestation neurologique la plus fréquente de l'infection par le VNO était l'encéphalite avec atteinte neuromusculaire subséquente. La diversité des observations cliniques et anatomopathologiques témoigne d'une atteinte diffuse du système nerveux central et périphérique. Le pronostic quant à la récupération neurologique et à la survie était réservé chez les patients plus âgés ou immunocompromis.

Can. J. Neurol. Sci. 2004; 31: 185-193

West Nile virus (WNV) is a member of the Flaviviridiae family along with other viruses such as Japanese encephalitis, St. Louis encephalitis and Kunjin virus. This virus is part of an enzootic cycle involving birds and, commonly, the Culex mosquito. ${ }^{1}$ The first documented report of WNV infection in humans in North America occurred in $1999 .{ }^{2}$ In the temperate climate of Canada and most of North America, WNV infectivity
From the University Health Network (JMB, RZK, WH, DM, JB, CP, CJ); University of Toronto Department of Medicine (JMB, RZK, JB,CP, CJ); Department of Medical Imaging (DM); Division of Neurology (JMB, RZK, CJ); Division of Neuropathology (WH); Division of Neuroradiology (DM); Division of Infectious Diseases (JB, CP); Laboratories Branch, Ministry of Health and Long Term Care (MF); Toronto, Ontario, Canada.

ReCEIVEd OCTOBER 20, 2003. ACCEPTEdin FinAlform February 25, $2004 .$. Reprint requests to: Cheryl Jaigobin, Toronto General Hospital, University Health Network, Eaton North 11-215, 200 Elizabeth Street, Toronto, ON M5G 2C4 Canada. 
emerges in summer and early fall secondary to the mosquito life cycle. $^{3}$

The incubation period for WNV infection is between three and 14 days. Symptomatic infection may consist of malaise, anorexia, nausea and vomiting, headache, myalgias, arthralgias, lymphadenopathy and a maculopapular or morbilliform rash. ${ }^{3}$ These symptoms are self-limiting and may last for up to one week. Only one in 150 infections results in severe neurological illness. ${ }^{4}$ Recognized neurological manifestations include encephalitis, meningitis, ataxia, cranial nerve palsies, polyradiculitis and acute flaccid paralysis similar to Guillain-Barré Syndrome (GBS). ${ }^{5}$ Risk factors for severe neurological disease include advanced age (>75 years), immunosuppression and diabetes mellitus. ${ }^{6}$

The present study was undertaken in an effort to better understand the spectrum of neurological disease associated with WNV infection and trends in diagnostic testing.

\section{MethodS}

All patients with WNV infection and neurological illness admitted to the University Health Network and Mount Sinai Hospital, (a network of four tertiary hospitals in Toronto), in August and September 2002 were identified and followed by the neurology consult service. The onset of all cases was between August 10 and Sept 20, 2002 during the West Nile epidemic in southern Ontario. ${ }^{7}$ In 2002, polymerase chain reaction preceded by the reverse transcriptase reaction (RT-PCR) for virus was not available and, due to limited availability of IgM enzyme-linked immunoabsorbant assay (ELISA) reagents, serological testing was performed on serum samples by hemagglutination inhibition (HAI) as previously described. ${ }^{8}$ Samples were frozen and retested by the IgM capture ELISA using kits obtained from PanBio Ltd, Windsor, Australia as recommended by the manufacturer. ${ }^{9}$ The diagnosis of WNV infection was based on a four-fold increase in WNV antibodies assayed by HAI, a single titer of 1:320 or greater by HAI, or positive IgM capture test. All positive results were confirmed by the plague reduction neutralization test, using standard protocols. These inclusion criteria are a modification of the US Centers for Disease Control and Prevention criteria. ${ }^{10}$ Additional serological data are included in a publication by several of the authors. ${ }^{11}$ Patient records were reviewed and information regarding clinical presentation, laboratory investigations, neuroimaging, electrodiagnostic studies and, if available, neuropathological assessments, was abstracted. Whenever possible, clinical follow-up assessments were performed. This study was approved by the University Health Network and Mount Sinai Hospital Research Ethics Boards.

\section{RESUlTS}

\section{A. Patient demographics}

Baseline characteristics and clinical presentations are summarized in Table 1. The series included five women and nine men, with a mean age of 59 years (range of 32-83 years). Five were immunocompromised; two patients received chronic immunosuppressive medications following organ transplantation, two patients had concurrent malignancy and recent chemotherapy, and a fifth patient had myelodysplasia. All five presented with encephalitis resulting in marked disability or death. Disease progression was characterized by clinical and pathological evidence of neuromuscular disease (weakness and reflex changes consistent with pathology at the level of the anterior horn cell and below), within days of presentation. Four patients required ongoing critical care and ultimately died of cardio-respiratory complications. Of those who died, two were immunocompromised and two were over 75 years of age. Cerebrospinal fluid studies for these patients are shown in Table 2.

\section{B. Clinical presentation}

The most common presentation was encephalitis (11/14, $78 \%$ ). The remaining patients presented with cerebellar ataxia with and without encephalitis $(2 / 14,14 \%)$ or neuromuscular disease with or without encephalitis (2/14, or 14\%) and meningitis $(1 / 14,7 \%)$. The neurological syndromes are outlined below.

\section{Central nervous system}

\section{Encephalitis}

Eleven patients presented with encephalitis with or without other neurological abnormalities. In this report, encephalitis refers to a constellation of symptoms including headache, fever, potential seizure activity and confusion. Fever occurred in all patients and, in one patient, occurred before admission to hospital. In the other patients' fever, the mean maximum temperature was 39.4 degrees Celsius while the median value was 39.6. Other common clinical features included headache, confusion and a maculopapular or morbilliform rash. Cerebrospinal fluid (CSF) analysis was abnormal in all of these patients demonstrating elevated white blood cell (WBC) counts (7-249 cells $/ \mu \mathrm{L})$ and protein values $(490$ - 1740mg/L). Routine cultures and cytological studies were negative. Neuroimaging revealed that three patients had leptomeningeal enhancement while two had changes consistent with rhombencephalitis and subcortical lesions. Elderly (age $>75$ years) and immunocompromised patients were more likely to progress to coma. Two immunocompromised patients with encephalitis rapidly deteriorated and developed abnormalities consistent with rhombencephalitis. Both patients subsequently died.

\section{Meningitis}

One patient presented with isolated meningitis characterized by headache, nuchal rigidity with positive tests of meningeal irritation, photophobia, nausea and a transient diplopia. Cerebrospinal fluid analysis demonstrated a raised WBC count $(658$ cells $/ \mu \mathrm{L})$ and elevated protein $(900 \mathrm{mg} / \mathrm{L})$. All other CSF and neuroimaging studies were normal. The patient made a complete recovery.

\section{Cerebellar ataxia}

Two patients presented with cerebellar ataxia, one in isolation and the other as part of a constellation of neurological symptoms. Gait ataxia in the absence of proprioceptive or visual disturbance was the main feature, with relative preservation of hemispheric function. On CSF studies, the WBC count was raised (22-44 cells/mL) with relatively normal protein $(340-550 \mathrm{mg} / \mathrm{L})$. Neuroimaging studies did not reveal cerebellar or brainstem lesions.

\section{Other}

Patient 4 presented with encephalitis and developed a thoracic 


\section{Table 1: Patient Demographics and Clinical Presentations}

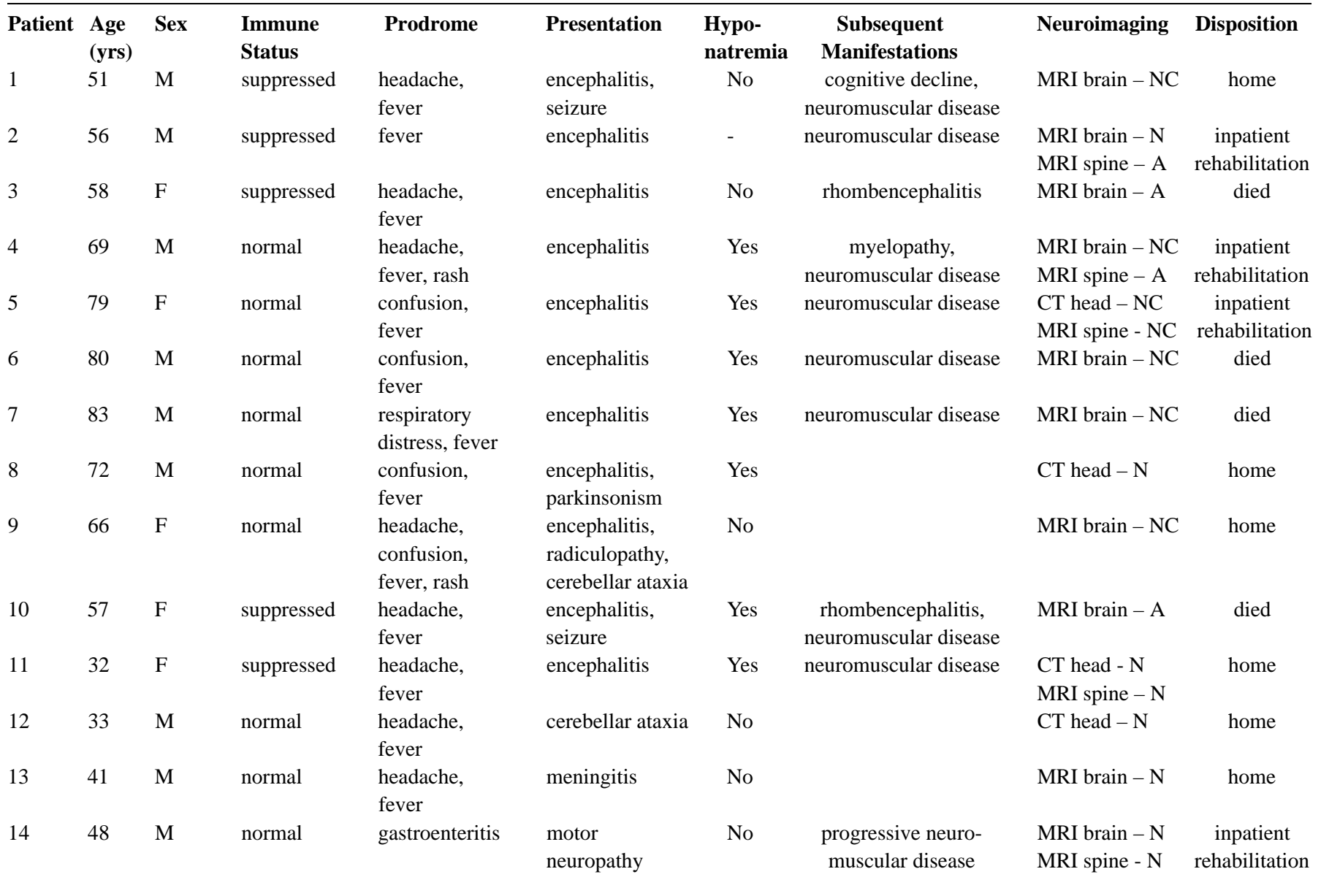

Hyponatremia defined as a serum sodium value less than $135 \mathrm{meq} / \mathrm{L}$.

Neuromuscular disease encompasses weakness and reflex changes consistent with pathology at the level of the anterior horn cell and below.

MRI imaging routinely included administration of gadolinium and the following sequences: DWI, FLAIR, T2, T1 pre and post gadolinium $(\mathrm{N}=$ normal, $\mathrm{NC}=$ non-contributory, $\mathrm{A}=$ abnormal $)$.

level myelopathy one week after admission. The symptoms consisted of lower extremity spasticity, paraparesis, bilateral extensor plantar responses, a thoracic sensory level and sphincter impairment. Electrodiagnostic studies revealed findings suggestive of a demyelinating polyneuropathy with secondary axonal degeneration. At three months there was minimal improvement.

A second patient with encephalitis demonstrated features of parkinsonism with tremor, rigidity and bradykinesia. A CT scan of the brain was normal and all symptoms resolved within weeks. There were no other cases of movement disorders.

\section{Neuromuscular involvement}

Eleven patients developed neuromuscular involvement; two presented at onset and the remainder during the course of encephalitis. Eight patients had electrodiagnostic testing (Tables 3 and 4) and a ninth patient had ventral grey matter and nerve root abnormalities on autopsy.

\section{Pure motor syndromes}

Seven patients had pure motor neuromuscular syndromes. Three patients, all comatose, developed a severe and diffuse syndrome of flaccid quadraparesis. Cerebrospinal fluid studies demonstrated both a raised WBC count $(7-249$ cells $/ \mu \mathrm{L})$ and protein level (560-830mg/L). Routine cultures and cytological studies were negative. Electrodiagnostic testing revealed a virtual absence of compound muscle action potentials or motor units but with fibrillation potentials, localizing the lesions to the anterior horn cell, ventral roots and/or the motor axons. All three patients subsequently died during admission from cardiorespiratory complications.

Two patients had a rapidly progressive asymmetric flaccid paralysis, one in the upper extremities and face without encephalitis, the other in the lower extremities within a week of encephalitis. Cerebrospinal fluid studies demonstrated a raised WBC count and protein (46 and 22 cells $/ \mu \mathrm{L}, 1480 \mathrm{mg} / \mathrm{L}$ and 

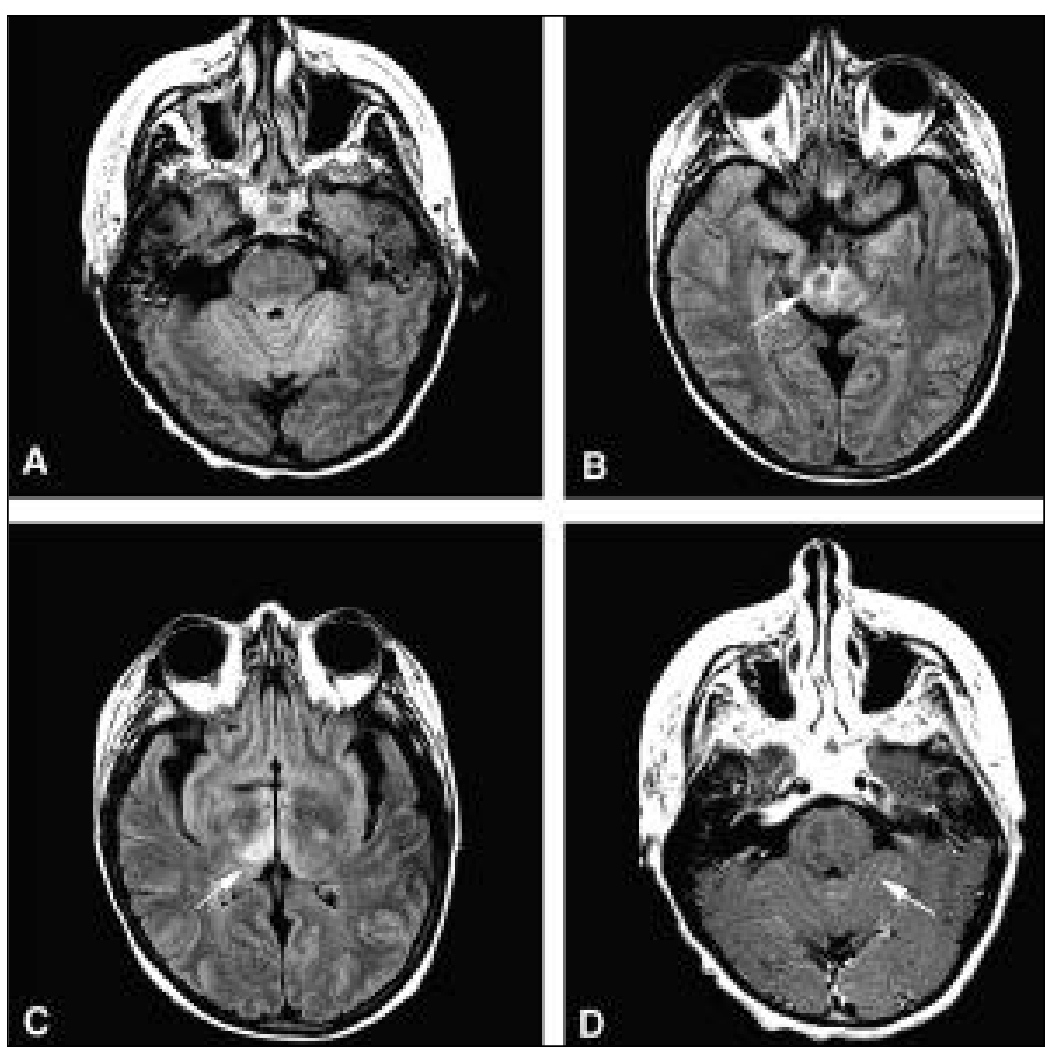

Figure 1: MRI abnormalities in posterior fossa and thalamus in patient with rhombencephalitis. $(A),(B)$, and $(C)$ are FLAIR images showing increased signal in the cerebellar vermis, superior aspect of the cerebellar hemispheres, midbrain and right thalamus (arrows). (D) Tl-weighted image after intravenous administration of gadolinium-DTPA showing enhancement of pial surface of cerebellar folia (arrow).
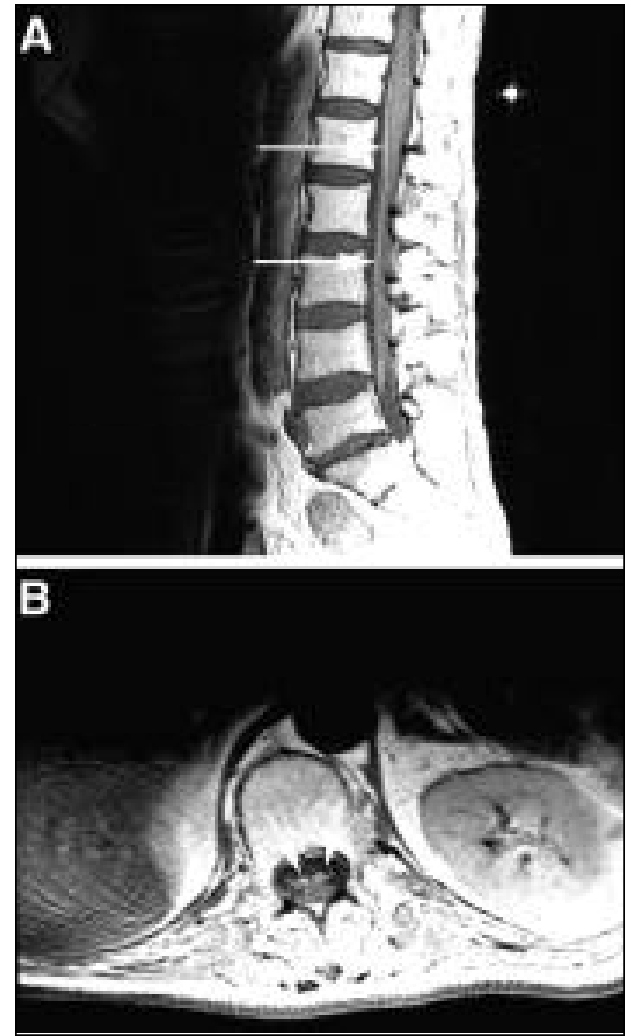

Figure 2: MRI abnormalities in patient with Guillain-Barré syndrome-like neuropathy.

Post gadolinium T1-weighted images of the spine demonstrate enhancement along the pial surface of the lower spinal cord and anterior roots of the cauda equina (arrows).
Table 2: Cerebrospinal fluid Profiles

\begin{tabular}{lccccr}
\hline Patient & \multicolumn{5}{c}{ CSFProfile } \\
& $\begin{array}{c}\text { WBC } \\
\text { (cells/mL) }\end{array}$ & $\begin{array}{c}\text { Neutrophils } \\
(\%)\end{array}$ & $\begin{array}{c}\text { Lymphocytes } \\
(\%)\end{array}$ & $(\%)$ & $\begin{array}{r}\text { Other } \\
\text { Protein } \\
(\mathrm{mg} / \mathrm{L})\end{array}$ \\
1 & 69 & 25 & 60 & 15 & 700 \\
2 & 9 & 50 & 50 & 0 & 900 \\
3 & 58 & 18 & 80 & 2 & 600 \\
4 & 32 & 83 & 9 & 8 & 630 \\
5 & 232 & 45 & 22 & 23 & 1740 \\
6 & 249 & 87 & 23 & 0 & 830 \\
7 & 7 & 0 & 100 & 0 & - \\
8 & 106 & 72 & 28 & 0 & 490 \\
9 & 44 & 23 & 77 & 0 & 550 \\
10 & 16 & 29 & 71 & 0 & 560 \\
11 & 22 & 10 & 88 & 2 & 950 \\
12 & 22 & 0.5 & 99.5 & 0 & 340 \\
13 & 658 & 23 & 77 & 0 & 900 \\
14 & 33 & 3 & 97 & 0 & 1480 \\
& & & & & \\
\hline
\end{tabular}

Cytology was performed on all CSF specimens and was negative for malignancy in all.
950mg/L, respectively). Cerebrospinal fluid cultures, cytology, and an extensive workup for systemic disease including malignancy were negative. Electrodiagnostic testing was consistent with a multifocal process involving anterior horn cells, the ventral roots or both, demonstrated by reduced motor amplitudes in multiple nerves, denervation including involvement of paraspinal muscles, increased F-wave latencies and normal sensory studies. The patient with the upper extremity involvement was initially treated with two courses of intravenous immunoglobulin (IVIg) at $2 \mathrm{~g} / \mathrm{kg}$ per course, but without any response.

Two additional patients had unilateral leg weakness and reflex loss without sensory abnormalities. Confirmatory electrodiagnostic studies were not available. Cerebrospinal fluid studies demonstrated an elevated WBC count ( $44-232$ cells $/ \mu \mathrm{L})$ and a protein range of $550-1740 \mathrm{mg} / \mathrm{L}$.

\section{Peripheral neuropathy}

This pattern of neuromuscular dysfunction was present in three patients. Patient 2 had reduced motor and sensory nerve amplitudes, reduced conduction velocities as well as conduction block, temporal dispersion in two nerves and increased F-wave latencies supporting a diagnosis of a demyelinating neuropathy with secondary axonal degeneration. Patient 4 had reduced 
Table 3: Motor Nerve Conduction Studies in 8 subjects with WNV Neuromuscular Involvement.

\begin{tabular}{|c|c|c|c|c|c|c|c|c|}
\hline Patient & $\begin{array}{l}\text { Tibial } \\
\text { DML } \\
(\mathrm{ms}) \\
N<5.5 \mathrm{~ms}\end{array}$ & $\begin{array}{l}\text { Tibial } \\
\text { CMAP } \\
\text { Amplitude } \\
(m v) N>3 m v\end{array}$ & $\begin{array}{l}\text { Tibial } \\
\text { MNCV } \\
(\mathrm{m} / \mathrm{s}) \\
N>39 \mathrm{~m} / \mathrm{s}\end{array}$ & $\begin{array}{l}\text { Tibial } \\
\text { f-wave } \\
(\mathrm{ms}) \\
N<56 \mathrm{~ms}\end{array}$ & $\begin{array}{l}\text { Peroneal } \\
\text { DML } \\
(\mathrm{ms}) \\
N<5.5 \mathrm{~ms}\end{array}$ & $\begin{array}{l}\text { Peroneal } \\
\text { CMAPAmplitude } \\
(\mathrm{mv}) \\
N>3 \mathrm{mv}\end{array}$ & $\begin{array}{l}\text { Peroneal } \\
\text { MNCV } \\
(\mathrm{m} / \mathrm{s}) \\
N>40 \mathrm{~m} / \mathrm{s}\end{array}$ & $\begin{array}{l}\text { Peroneal } \\
\text { f-wave } \\
(\mathrm{ms}) \\
N<56 \mathrm{~ms}\end{array}$ \\
\hline 1 & 6.3 & 0.9 & 54.3 & 62.1 & 4.5 & 1.0 & 55.6 & absent \\
\hline $2 *$ & 4.2 & 0.9 & 32.8 & 59.1 & 5.2 & 0.3 & 50 & absent \\
\hline $4^{*}$ & 6.8 & 1.0 & 31 & 86.1 & 9.2 & 1.0 & 31 & 80.9 \\
\hline 6 & absent & absent & absent & absent & absent & absent & absent & absent \\
\hline 7 & absent & absent & absent & absent & absent & absent & absent & absent \\
\hline 10 & absent & absent & absent & absent & absent & absent & absent & absent \\
\hline 11 & 5.8 & 0.8 & 35.5 & absent & 2.5 & 0.2 & absent & absent \\
\hline \multirow[t]{3}{*}{$14 \dagger$} & 4.8 & 0.6 & 32.3 & absent & absent & absent & absent & absent \\
\hline & $\begin{array}{l}\text { Median } \\
\text { DML } \\
(\mathrm{ms})\end{array}$ & $\begin{array}{l}\text { Median } \\
\text { CMAP } \\
\text { Amplitude } \\
\text { (mv) }\end{array}$ & $\begin{array}{l}\text { Median } \\
\text { MNCV } \\
(\mathbf{m} / \mathbf{s})\end{array}$ & $\begin{array}{l}\text { Median } \\
\text { f-wave } \\
(\mathrm{ms})\end{array}$ & $\begin{array}{l}\text { Ulnar-wrist } \\
\text { DML } \\
(\mathrm{ms})\end{array}$ & $\begin{array}{l}\text { Ulnar-wrist } \\
\text { CMAP } \\
\text { Amplitude } \\
\text { (mv) }\end{array}$ & $\begin{array}{l}\text { Ulnar-wrist } \\
\text { MNCV } \\
(\mathbf{m} / \mathbf{s})\end{array}$ & $\begin{array}{l}\text { Ulnar-wrist } \\
\text { f-wave } \\
(\mathrm{ms})\end{array}$ \\
\hline & $N<4.5$ & $N>4 m v$ & $N>50 \mathrm{~m} / \mathrm{s}$ & $\mathrm{N}<32 \mathrm{~ms}$ & $\mathrm{~N}<4.0 \mathrm{~ms}$ & $N>4 m v$ & $N>50 \mathrm{~m} / \mathrm{s}$ & $\mathrm{N}<32 \mathrm{~ms}$ \\
\hline 1 & 4.0 & 4.3 & 48.9 & 32.2 & 2.5 & 8.8 & 53.8 & 28.8 \\
\hline $2 *$ & 4.6 & 0.1 & absent & absent & 3.5 & 0.4 & 52.3 & absent \\
\hline $4 *$ & 3.6 & $7.2 \ddagger$ & 41 & 37.7 & NT & NT & NT & NT \\
\hline 6 & absent & absent & absent & absent & absent & absent & absent & absent \\
\hline 7 & 8.4 & 0.3 & 26.4 & absent & 5.0 & 0.6 & 23.3 & absent \\
\hline 10 & absent & absent & absent & absent & absent & absent & absent & absent \\
\hline 11 & NT & NT & NT & NT & NT & NT & NT & NT \\
\hline 14 & 4.7 & 4.4 & 50.9 & 35.0 & 3.7 & 7.4 & 56.5 & 36.9 \\
\hline
\end{tabular}

$\mathrm{CMAP}=$ compound motor action potential; $\mathrm{MNCV}=$ motor nerve conduction velocity; $\mathrm{DML}=$ distal motor latency; $\mathrm{mv}=$ millivolts; $\mathrm{ms}=$ milliseconds; $\mathrm{m} / \mathrm{s}=$ meters $/$ second $; \mathrm{NT}=$ not tested.

$\dagger$ Patient 14 had a history of a remote pelvic injury with peripheral nerve damage

$\$$ Patient 4 had his nerve conduction studies performed in a laboratory which used peak to peak measures for amplitude for which a normal value is $\mathrm{N}>7$

\section{Table 4: Needle Electromyography in 8 Subjects with WNV Neuromuscular Involvement.}

\begin{tabular}{llcll}
\hline Patient & Muscles & Fibs/PSWs & Motorunit morphology & Motor Unit Recruitment \\
1 & TA,VL & $1+$ & Polyphasic, increased duration and amplitude & Moderately reduced number \\
2 & G,TA & $1-2+$ & Normal morphology & Moderately reduced number \\
4 & G,TA,VL,GM & $1-2+$ & Polyphasic, increased duration and amplitude & Moderately reduced number \\
6 & TA,VL & $3+$ & No units & No units \\
7 & G,TA,VL & $3+$ & No units & No units \\
10 & TA,VL & $3+$ & No units & No units \\
11 & G,TA,GM,L4-5 paraspinals & $1-3+$ & Normal morphology & Mildly reduced number \\
14 & APB,FDI & $3+$ & Increased duration and amplitude & Moderately reduced
\end{tabular}

Fibs = fibrillations; PSWs = positive sharp waves; $\mathrm{G}=$ gastrocnemius; $\mathrm{TA}=$ tibialis anterior; $\mathrm{GM}=$ gluteus medius; $\mathrm{APB}=$ abductor pollicis brevis; FDI $=$ first dorsal interosseous; $\mathrm{VL}=$ vastus lateralis 

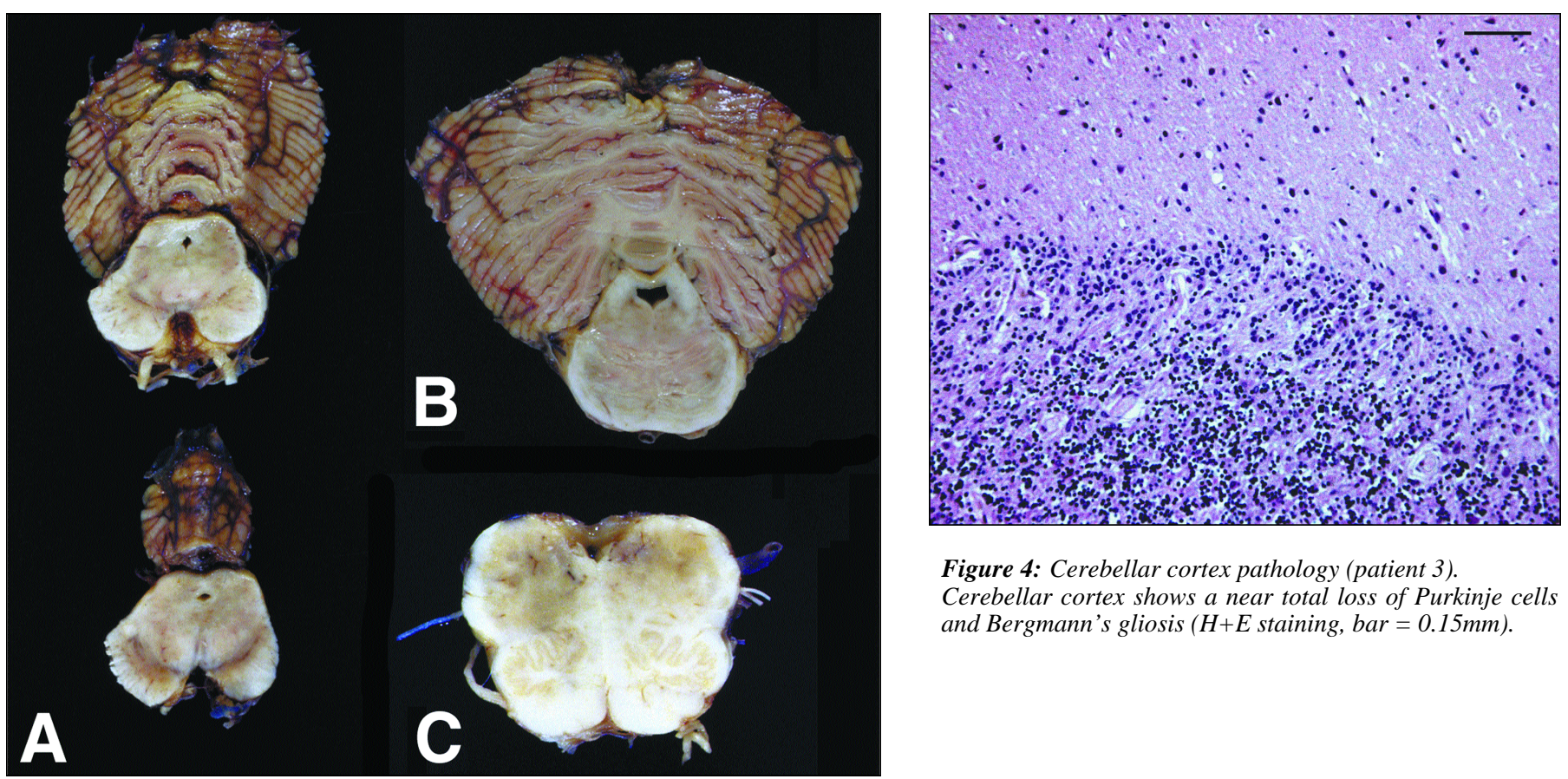

Figure 4: Cerebellar cortex pathology (patient 3).

Cerebellar cortex shows a near total loss of Purkinje cells and Bergmann's gliosis $(H+E$ staining, bar $=0.15 \mathrm{~mm})$.

Figure 3: Gross brainstem specimen of patient 3 with rhombencephalitis.

(A) Midbrain with patchy discolouration seen about the aqueduct. (B) Necrotic foci in the basis pontis. $(C)$ Duskiness about the floor of the 4 th ventricle, representing areas of inflammation and congestion.
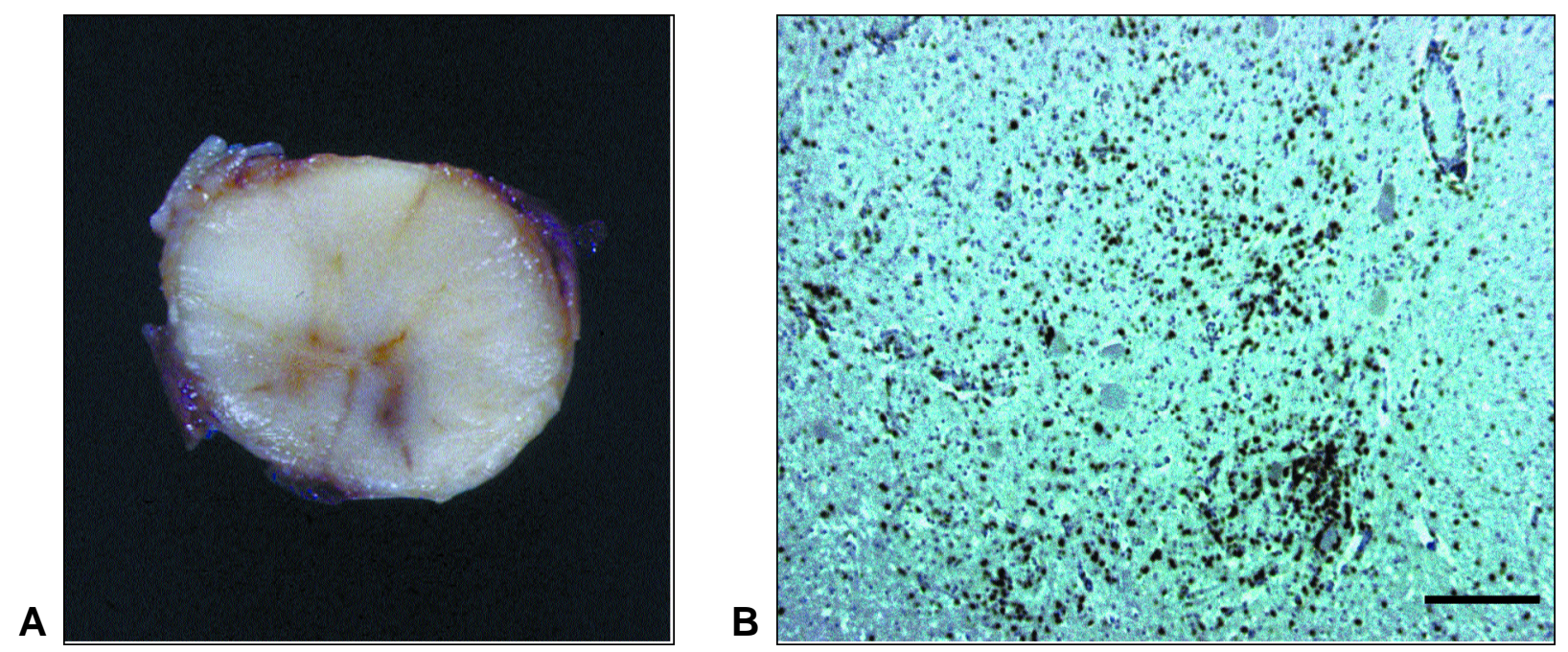

Figure 5: Gross and microscopic images of spinal cord showing congestion and cytotoxic T-cells in grey matter (patient 3).

Transverse section of spinal cord (A) shows focal congestion of the anterior horn. Immunohistochemical studies for CD8 reactive T cells demonstrate innumerable cytotoxic $T$ cells, mainly in the grey matter of the spinal cord $(B)$. $($ bar $=0.5 \mathrm{~mm})$.

motor nerve amplitudes, reduced conduction velocities, borderline temporal dispersion in one nerve and increased Fwave latencies but without conduction block. This patient was diagnosed with possible demyelinating neuropathy with secondary axonal degeneration (Tables 3 and 4). The acute demyelinating neuropathy was accompanied by enhancement of lumbar roots in the lumbar MRI. Patient 4 also had clinical evidence of a coexistent myelopathy. A third patient had a sensorimotor axonal neuropathy. In these patients, the CSF studies demonstrated a pleocytosis $(9-32$ cells $/ \mu \mathrm{L})$ and elevated CSF protein $(630-900 \mathrm{mg} / \mathrm{L})$.

\section{Follow-up}

Several patients have been seen in follow-up since their hospitalizations. At the three to six month mark, patients 1 and 2, 
who had encephalitis and subsequent neuropathy had worsened, with progressive neuromuscular dysfunction and cognitive changes in the case of patient 1 . There was minimal recovery in patients 4, 5, 11 and 14, who were still significantly weak and disabled in ambulation and other activities of daily living. Patients 8, 12 and 13, who had no neuromuscular involvement, had complete recovery within weeks of presentation. Patient 9, had a very good recovery of motor and cerebellar function with residual changes in executive function.

\section{Laboratory findings}

Hyponatremia was present in 7/14 patients, all of whom had encephalitis (see Table 1).

With respect to the microbiological diagnosis, eleven patients had a four fold rise in West Nile antibodies detected by HAI, two had a two-fold rise in HAI titre with a positive IgM capture ELISA, while one patient, diagnosed retrospectively, had a single high West Nile HAI titre (1/640) and positive IgM capture ELISA. During the 2002 season, the IgM capture assay was not available and the HAI test was used. In 5/14 cases the HAI test remained negative for a mean of 17 days after the onset of symptoms. In contrast, the IgM capture ELISA was negative 13 days after symptom onset in a single patient who had undergone stem cell autotransplantation for treatment of lymphoma. In this patient and another, who was immunocompromised after transplantation, the HAI test remained negative for at least 24 days after the onset of symptoms while the $\operatorname{IgM}$ capture assay was positive at 21 and six days respectively.

\section{Radiology}

Radiological investigations included CT and MRI (Table 1). Computed tomography studies showed no evidence of encephalitis; however this modality was only used during the initial phase of the infection. An MRI was more sensitive showing inflammatory changes with two major patterns of CNS involvement. The first pattern of disease showed abnormalities in the brainstem, cerebellum, thalamus and basal ganglia with sparing of the temporal lobes and cerebral hemispheres. The involved structures demonstrated increased $\mathrm{T} 2$ signal and were mildly swollen. Gadolinium-DTPA administration was unremarkable except for subtle enhancement of the pial surface of the cerebellar folia (Figure 1). The imaging features indicated both leptomeningeal and parenchymal inflammation. Findings in the second pattern, seen in two patients, were limited to the distal spinal cord and cauda equina. Increased signal was observed on T1-weighted images following intravenous administration of gadolinium along the pial surface of the distal spinal cord and cauda equina indicating leptomeningeal inflammation (Figure 2).

\section{E. Pathology}

Autopsy with examination of the brain and spinal cord was performed on patient 3 , one of the two patients with rhombencephalitis. The brain was diffusely swollen and the gyri flattened. The basal ganglia, thalami, brainstem and spinal cord showed dusky areas. Irregular areas of softening were present in the basis pontis. Microscopically, the nervous system and its coverings demonstrated widespread inflammation. Both the central and peripheral nervous systems were involved. The most severely involved areas were within the anatomical boundaries of the globus pallidum, the thalamus, the brainstem (Figure 3), cerebellum and the grey matter of the spinal cord. The basis pontis was the most obvious focus of necrosis; however, tissue necrosis was also evident in the globus pallidum and thalamus. The tissue was very edematous at these sites. A lymphoplasmacytic inflammatory infiltrate was associated with innumerable macrophage and reactive gliosis. Although both B and $\mathrm{T}$ cells were present, the inflammatory cells infiltrate was rich in CD8 reactive cytotoxic/killer $\mathrm{T}$ cells. Focally, plasma cells containing Russel bodies were easily found. Swollen axons were present and scattered microscopic foci of tissue calcification involved the neuropil and vessel walls. The cerebellum revealed a near total loss of Purkinje cells and a brisk, reactive Bergmann's gliosis (Figure 4). The cerebellar white matter, far more abnormal than the cerebral white matter, was gliotic, edematous and demonstrated both myelin breakdown and axonal swellings. The deep cerebellar nuclei were intensely inflamed. Inflammation involved mainly the grey matter of the spinal cord (i.e. a poliomyelitic pattern) throughout its length (Figure 5). Inflammation also involved the roots, both dorsal and ventral, and the dorsal root ganglia.

\section{DiscuSsion}

Encephalitis, which occurred in $78 \%$ of patients, was by far the most common presentation of West Nile virus mediated neurological illness in our cohort. More surprisingly, $82 \%$ of these encephalitis patients developed neuromuscular dysfunction within days of disease onset. This neuromuscular dysfunction took the form of a pure motor syndrome in seven patients, a demyelinating neuropathy in one patient and possibly in a second, and a sensorimotor axonopathy in one patient. The final patient in this group had autopsy evidence of such changes in the neuroaxis diffusely. Neuromuscular deficits often became chronic conditions with minimal if any recovery several months after onset, as seen in several patients. Deaths in this cohort occurred in patients who were of advanced age or immunocompromised, who seemed particularly vulnerable to rhombencephalitis. Uncommon presentations in this outbreak included cerebellar ataxia, myelopathy and parkinsonism. Other movement disorders were not seen.

In one case of fatal rhombencephalitis, autopsy demonstrated diffuse swelling and inflammatory changes with necrosis in cortical, subcortical and brainstem structures. In the spinal cord there was clear involvement of the ventral grey matter, nerve roots and dorsal root ganglia. Certain neuronal populations appeared to be especially vulnerable to WNV infection. A near total loss of cerebellar Purkinje cells suggests that there is predilection for this cell type in addition to anterior horn cells, mirroring several animal studies. ${ }^{12-14}$ The findings on autopsy paralleled the central and peripheral patterns of disease seen on imaging studies. In patients with brain involvement, the deep nuclei, brainstem, and cerebellum were affected; a pattern very distinct from the mesial temporal involvement seen with herpes encephalitis. In patients with electrodiagnostic evidence of a demyelinating neuropathy, the surfaces of the distal spinal cord and ventral cauda equina were affected.

The findings in Toronto, are for the most part, in keeping with earlier studies of WNVinfection such as those in New York City ${ }^{2}$ and Israel, ${ }^{6,15}$ as well as more recent outbreaks in Louisiana and 
Cleveland. ${ }^{16,17}$ In all, encephalitis and meningitis were the most common presenting illnesses, and in New York and Israel, similar risk factors for poor prognosis (advanced age and immunocompromise) were seen. In the New York study, weakness was reported in only roughly one quarter of patients, and acute flaccid paralysis reported even less frequently in only $10 \%$ of patients. Compared to these reports, neuromuscular involvement was present in a greater proportion of our patients with a clear temporal pattern of these abnormalities following encephalitis.

More closely resembling our experience was that of Sejvar et $\mathrm{al}^{16}$ in Louisiana. In comparison to the outbreak in Toronto, fewer patients in the Louisiana outbreak had acute flaccid paralysis-like dysfunction, which was also felt to be attributable to anterior horn cell dysfunction in many cases (however, electrophysiological data was not supplied). Also common to both studies is the lack of significant improvement in the months following acute flaccid paralysis and the occasional case of cognitive change. Even more striking was the prevalence of movement disorders in Louisiana, which occurred in all but one of their cases, commonly in the form of dyskinesias, tremor and myoclonus. In Toronto, only one patient had any discernable movement disorder in the form of rigidity, tremor and bradykinesia, labeled as parkinsonism. Finally, mortality was higher in Toronto, possibly as a function of the comorbidities and ages of the patients.

In Cleveland, ${ }^{17}$ there were differences in the types of neuropathy seen as compared to Toronto. While demyelinating neuropathy was seen in patients in the Toronto group and has been reported in other outbreaks, ${ }^{18}$ it was absent in the Cleveland cohort. Also absent from their series were any apparent cases of rhombencephalitis nor any mention of patients in an immunocompromised state. The subgroup of immunocompromised patients was identified in our study, as well as in several others, with increased morbidity and mortality. ${ }^{2,6}$

As this was a retrospective series, we were not able to rigorously compare the HAI and $\operatorname{IgM}$ capture assays as to the difference in time to seroconversion. However, the data on serological testing clearly show that the $\operatorname{IgM}$ capture assay is superior to the HAI test. The advantages are that more patients were positive on the first serum specimen (12/14 compared to $8 / 14$ ), and paired serum samples (acute and convalescent) are not needed, and the test is not as technically demanding. ${ }^{9}$ The superiority of the IgM test was most obvious in the two critically ill immunocompromised patients who would have the most to gain if an effective treatment were found. ${ }^{19,20}$ Some immunocompromised patients have delayed seroconversion even by IgM capture. In these cases viremia may be prolonged and a combination of IgM capture ELISA and RT-PCR of the CSF should be used to make the diagnosis as early as possible. ${ }^{21,22}$ Early diagnosis would be essential for timely institution of potential therapies such as West Nile hyperimmune serum or interferon $\alpha-2 b$.

Despite the trends we have seen in this cohort, there are limitations in this study. One major limitation is potential selection bias. Our cohort consisted of patients admitted to tertiary referral center and may represent the severe spectrum of WNV infection mediated neurological disease. It is possible that patients with milder symptoms or other neurological patterns of disease were not evaluated or admitted to hospital. Because this represented the first year of WNV infection in Ontario, low suspicion and the available microbiological testing may have resulted in an under-diagnosis of WNV infection.

West Nile virus is a cause of significant neurological morbidity and mortality, with the elderly and immunocompromised at greater risk. The most common neurological manifestation of WNV infection is encephalitis, which can occur with meningeal irritation. Other less common manifestations include rhombencephalitis, cerebellar ataxia and myelopathy. Movement disorders, although rare in this cohort, have been reported with moderate frequency elsewhere. The majority of our patients developed subsequent neuromuscular disease. Although most developed an anterior horn cell or axonal syndrome, a demyelinating neuropathy was also present, but was less common. Radiological and pathological studies confirmed involvement of diffuse regions of the brain, especially the globus pallidus, thalamus, brainstem structures and cerebellum with a profound loss of Purkinje cells. In the spinal cord, there was involvement of ventral grey matter, nerve roots and dorsal root ganglia.

Investigations and diagnostic testing for WNV infection should consist of the currently accepted WNV testing (the IgM capture assay is a more sensitive test than HAI) while CSF studies remain an important method to rule out malignancy, and other infectious or inflammatory etiologies. While neuroimaging can include a preliminary $\mathrm{CT}$ of the brain, there are no specific CT changes associated with WNV infection. We recommend MRI with gadolinium to evaluate the basal ganglia, thalamus, brainstem structures and cerebellum, all of which appear to be vulnerable to WNV. An MRI of the spinal cord may show nerve root enhancement but this is not sufficient to rule out GuillainBarré syndrome (GBS). We also recommend electrodiagnostic testing in all patients with weakness and suspected WNV infection to distinguish it from GBS as well as to monitor the evolution of their neuromuscular disease if present. Electrodiagnostic testing for all WNVpatients who have become ventilator dependent with apparent coma may help distinguish a central cause for coma from a more peripheral, "locked-in" state. However, a small subgroup of patients with WNV infection will have an electrodiagnostic profile similar to GBS. In this setting, WNV serology and CSF studies will be instrumental in the diagnosis and guide treatment, which is well-understood in GBS but remains undefined in WNV infection. The timing of neuromuscular complications is variable and may develop after discharge from hospital. We therefore recommend prompt follow-up and thorough neurological assessment in the outpatient setting given the potential delayed and long-term complications.

\section{REFERENCES}

1. Turell MJ, Sardelis MR, Dohm DJ, O'Guinn ML. Potential North American vectors of West Nile virus. Ann NY Acad Sci 2001; 951: 317-324.

2. Nash D, Mostashari F, Fine A, et al. The outbreak of West Nile virus infection in the New York City area in 1999. N Engl J Med 2001; 344: 1807-1814.

3. Campbell GL, Marfin AA, Lanciotti RS, Gubler DJ. West Nile Virus. Lancet Infect Dis 2002; 2: 519-529.

4. Mostashari F, Bunning ML, Kitsutani PT, et al. Epidemic West Nile 
encephalitis, New York, 1999: results of a household-based seroepidemiological survey. Lancet 2001; 358: 261-264.

5. Peterson LR, Martin AA. West Nile virus: a primer for the clinician. Ann Intern Med 2002; 137: 173-179.

6. Chowers MY, Lang R, Nassar F, et al. Clinical characteristics of the West Nile fever outbreak, Israel, 2000. Emerging Infect Dis 2001; 7: 675-678.

7. Halton Region Public Health. WNV surveillance data in Halton 2002. 5-13-0003. Ref Type: Internet Communication.

8. Clarke D, Casals J. Techniques for hemagglutination inhibition with arthropod-borne viruses. Am J Trop Med Hyg 1958; 7:561-573.

9. Martin DA, Muth DA, Brown T, et al. Standardization of immunoglobulin $\mathrm{M}$ capture enzyme-linked immunosorbent assays for routine diagnosis of arboviral infections. J Clin Microbiol 2000; 38: 1823-1826.

10. Centers for Disease Control and Prevention. Epidemic/epizootic West Nile virus in the United States: revised guidelines for surveillance, prevention, and control. Available at: www.cdc.gov/ncidod/dvbid/westnile/resources/wnv-guidelinesapr-2001.pdf. Accessed May 5, 2003.

11. Pepperell C, Rau N, Krajden S, et al. West Nile virus infection in 2002: morbidity and mortality among patients admitted to hospital in southcentral Ontario. Can Med Assoc J 2003; 168: 1399-1405.

12. Xiao S, Guzman H, Zhang H, Travassos da Rosa APA, Tesh RB. West Nile virus infection in the golden hamster (Mesocricetus auratua): a model for West Nile encephalitis. Emerg Infect Dis 2001; 7: 714-721.
13. Manulidis EE. Neuropathology of experimental West Nile virus infection in monkeys. J Neuropath Exp Neurol 1956;15: 448-460.

14. Steele KE, Linn MJ, Schoepp RJ, et al. Pathology of fatal West Nile Virus infections in native and exotic birds during the 1999 outbreak in New York City, New York. Vet Pathol 2000; 37: 208224.

15. Klein C, Kimiagar I, Pollak L, et al. Neurological features of West Nile virus infection during the 2000 outbreak in a regional hospital in Israel. J Neurol Sci 2002; 200: 63-66.

16. Sejvar JJ, Haddad M, Tierney BC et al. Neurological manifestations and outcome of West Nile virus infection. JAMA2003; 290: 511515.

17. Jeha LE, Sila CA, Lederman RJ, et al. West Nile virus infection: a new acute paralytic illness. Neurology 2003; 61: 55-59.

18. Li J, Loeb JA, Shy ME, et al. Asymmetric flaccid paralysis: a neuromuscular presentation of West Nile virus infection. Ann Neurol 2003; 53: 703-710.

19. Iwamoto M, Jernigan DB, Guasch A, et al. Transmission of West Nile virus from an organ donor to four transplant recipients. $\mathrm{N}$ Engl J Med 2003; 348: 2196-2203.

20. Pealer LN, Marfin AA, Petersen LR, et al. Transmission of West Nile virus through blood transfusion in the United States in 2002. N Engl J Med 2003; 349: 1236-1245.

21. Hong DS, Jacobson KL, Raad II, et al. West Nile encephalitis in 2 hematopoietic stem cell transplant recipients: case series and literature review. Clin Infect Dis 2003; 37: 1044-1049.

22. Petersen LR, Marfin AA, Gubler DJ. West Nile virus. JAMA2003; 290: 524-528. 